\title{
Type 2 Diabetes Mellitus in Class II and III Obesity: Prevalence, Associated Factors, and Correlation between Glycemic Parameters and Body Mass Index
}

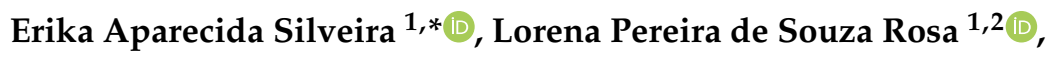 \\ Annelisa Silva e Alves de Carvalho Santos ${ }^{1,3}{ }^{(}$, Camila Kellen de Souza Cardoso ${ }^{1,4}(\mathbb{B}$ \\ and Matias Noll 1,5 \\ 1 Post-Graduate Program in Health Sciences, School of Medicine, Federal University of Goiás, \\ Goiás 74605-050, Brazil; lorenapsrosa@yahoo.com.br (L.P.d.S.R.); annelisanut@gmail.com (A.S.e.A.d.C.S.); \\ camilacardoso_nut@hotmail.com (C.K.d.S.C.); matiasnoll@yahoo.com.br (M.N.) \\ 2 Federal Institute of Goiás, Goiânia Oeste Campus, Goiás 74270-040, Brazil \\ 3 United College of Campinas, Goiás 74535-040, Brazil \\ 4 Nutrition Course, School of Social and Health Sciences, Pontifical Catholic University of Goiás, \\ Goiás 74605-010, Brazil \\ 5 Instituto Federal Goiano, Ceres Campus, Goiás 76310-000, Brazil \\ * Correspondence: erikasil@terra.com.br
}

Received: 19 April 2020; Accepted: 27 May 2020; Published: 2 June 2020

\begin{abstract}
Despite the worldwide growth of class II and III obesity, the factors associated with type 2 diabetes mellitus (T2DM) in these obese individuals are not widely understood. Moreover, no study has investigated these associations in South America. Our study aimed to investigate the prevalence of T2DM and its associated factors, with an emphasis on biochemical parameters and eating habits, in class II and III obese individuals. We also aimed to analyze the correlation between glycemic parameters and body mass index (BMI). Baseline data from a randomized clinical trial (DieTBra Trial) of 150 class II and III obese individuals (BMI $>35 \mathrm{~kg} / \mathrm{m}^{2}$ ) was used. An accelerometer, Food Frequency Questionnaire, and bioimpedance analysis were used to assess physical activity levels, eating habits, and body composition, respectively. Blood was collected after $12 \mathrm{~h}$ of fasting. Hierarchical multivariate Poisson regression was performed, and prevalence ratios (PRs) were calculated. Correlations between glycemic parameters (fasting blood glucose, glycosylated hemoglobin, homeostasis model assessment of insulin resistance (HOMA-IR), and insulin) and BMI were also analyzed. The prevalence of T2DM was $40.0 \%$ (95\% CI, 32.1-48.3), high fasting blood glucose level was 19.33\% (95\% CI, 13.3-26.6), and high glycosylated hemoglobin was 32.67\% (95\% CI, 25.2-40.8). Age $\geq 50$ years ( $\mathrm{PR}=3.17,95 \%$ CI, 1.26-7.98) was significantly associated with T2DM; there was a positive linear trend between age and T2DM $(p=0.011)$. Multivariate analysis showed an association with educational level $(\mathrm{PR}=1.49$, $1.07-2.09, p=0.018)$, nonconsumption of whole grains daily ( $\mathrm{PR}=1.67,1.00-2.80, p=0.049)$, and high HOMA-IR ( $\mathrm{PR}=1.54,1.08-2.18, p=0.016)$. We found a high prevalence of T2DM and no significant correlations between BMI and glycemic parameters.
\end{abstract}

Keywords: severe obesity; diabetes; insulin resistance; food consumption; whole grains; HOMA-IR

\section{Introduction}

Diabetes and obesity are considered serious public health concerns worldwide, especially with the exponential growth of class II and III obesity in recent decades [1-4]. Approximately 463 million people worldwide are diabetic, of whom 90\% have type 2 diabetes mellitus (T2DM) [4]. These diseases are independently known to cause serious health complications, with risks of cardiovascular diseases, 
higher mortality, low quality of life, and increased public health spending; however, when these disease occur concurrently, their negative effects on health, health systems, and mortality are even greater $[1,3,4]$. There are few studies on T2DM in obese individuals [5,6], and even fewer on those with higher obesity levels, such as class II and III [7]. The few studies on T2DM associated with higher obesity classes are related to surgical procedures [8-10].

In this context, it is important to understand the factors associated with T2DM, especially in class II and III obesity, as these classes have presented the greatest growth. It is also relevant to understand if body composition [5] and food consumption variables [11-13] play a role in the analysis of associated factors. Eating behavior is an important environmental factor to consider in obesity, as the evaluation of food groups is essential [11]. Another aspect to be analyzed is whether increased body mass index (BMI) can modify glycemic parameters in these higher obesity categories. More studies using these approaches and further information on these aspects will be important to increase knowledge about T2DM in class II and III obesity and improve prevention, control, and treatment protocols in different clinical settings $[12,14]$.

Despite the relationship between T2DM and obesity, few studies have investigated the extent of the problem in class II and III obesity and whether food consumption, body composition, biochemical/glycemic parameters, and higher BMI increase the risk of T2DM in this population $\left(\mathrm{BMI} \geq 35 \mathrm{~kg} / \mathrm{m}^{2}\right)[7,12]$, especially in patients not undergoing bariatric surgery. When reviewing the existing literature, we found that studies of this association in South American populations were lacking, despite this population presenting an increased prevalence of class II and III obesity over the last decade [1]. Therefore, the objectives of the present study were to investigate the prevalence of T2DM and its associated factors, with an emphasis on biochemical parameters and eating habits, in class II and III obese individuals. Furthermore, we aimed to analyze the correlation between glycemic parameters and BMI. The results of this study may support clinical guidelines and public health policies targeting class II and III obesity.

\section{Material and Methods}

\subsection{Study Design and Participants}

This study used baseline data from the randomized clinical trial entitled "Effect of nutritional intervention and olive oil in severe obesity (DieTBra Trial)," registered on the ClinicalTrials.gov platform (NCT02463435). Further methodological details can be found in DieTBra Trial articles with different outcomes, published elsewhere [2,15-17].

All class II and III obese individuals (BMI $\geq 35 \mathrm{~kg} / \mathrm{m}^{2}$ ) from the Brazilian Unified Health System (UHS) of primary healthcare were referred to the Nutrition and Severe Obesity Clinic (ANOG/HC/UFG). At the time of study, ANOG was the only reference ambulatory to treat class II and III obesity in the metropolitan region of Goiânia, in the Midwest of Brazil. All obese class II and III individuals from UHS were invited to participate in the DieTBra Trial study and eligibility criteria were applied. The inclusion criteria were BMI $\geq 35 \mathrm{~kg} / \mathrm{m}^{2}$, both sexes, age between 18 and 64 years, and a residence in the city or in the metropolitan region of Goiânia, Brazil. The exclusion criteria were use of insulin and/or a medical diagnosis of type 1 diabetes, bariatric surgery, pregnancy and/or lactation, special needs, use of antiobesity drugs with a body weight reduction of $>8 \%$ in the previous 3 months, nutritional or medical monitoring for weight loss or some type of nutritional treatment, use of a pacemaker, and presence of metal rods and/or screws in the body. Therefore, the individuals selected for this study constitute a representative group of individuals with class II or III obesity from the primary healthcare system of UHS. 


\subsection{Sociodemographic Data, Lifestyle, and Eating Habits}

Information on educational level (years of study), economic class, marital status, color, age, and sex was collected. Lifestyle variables included smoking habits (smoker/ex-smoker and nonsmoker/never smoked) and level of physical activity (PA).

The PA level was assessed using an Actigraph accelerometer model wGT3X (Actigraph, Pensacola, FL, USA) positioned on the posterior side of the nondominant wrist. The participants were individually instructed to use the device $24 \mathrm{~h}$ a day for 6 consecutive days. ActiLife 6 software (Actigraph, Pensacola, FL, USA) was used for data processing. The recommendation to classify the PA level was $\geq 150 \mathrm{~min} /$ week of moderate to vigorous aerobic PA. The accelerometer provided the daily mean number of minutes spent on moderate and vigorous PA, which was multiplied by 7 days a week to obtain the mean time of moderate and vigorous PA per week lasting at least $10 \mathrm{~min}$ [18].

The Food Frequency Questionnaire (FFQ) was used to assess eating habits, which included details about the type of food consumed within each food group [19]. Sugary drink consumption included soft drinks, fruit nectar, and powdered drinks with no differentiation between types (diet/light or conventional).

\subsection{Body Composition and Anthropometry}

Body weight was measured in kilograms using a digital electronic scale (Welmy ${ }^{\circledR}$, Santa Barbara d'Oeste, SP, Brazil), with a capacity of up to $200 \mathrm{~kg}$ and an accuracy of $100 \mathrm{~g}$. Height was measured using a stadiometer coupled to the scale with an accuracy of $0.1 \mathrm{~cm}$ [20]. The BMI classifications used were recommended by the World Health Organization [21].

Obesity was assessed using bioimpedance analysis (BIA) with the Inbody S10 ${ }^{\circledR}$ multifrequency tetrapolar bioimpedance analyzer (Inbody, Gangnam-Gu, Seoul, Republic of Korea) [22]. All participants were instructed on the proper preparation and performance of the exam by receiving a folder containing the necessary information, such as to maintain hydration levels on the day of the exam, not to do vigorous PA the day before, and not to consume coffee, tea, cola, energy, or alcoholic drinks the day before [23]. The variables of body composition (total fat percentage, total fat mass in kilograms, and fat-free mass in kilograms) were categorized into quartiles according to distribution differences by sex.

\subsection{Biochemical Tests and Health Condition}

Blood samples were collected after a $12 \mathrm{~h}$ fast by a qualified professional, following high-quality standards both in the collection and analysis of the material. The lipid profile was analyzed using the following variables: hypercholesterolemia (total cholesterol $\geq 200 \mathrm{mg} / \mathrm{dL}$ ), hypertriglyceridemia (triglycerides $\geq 150 \mathrm{mg} / \mathrm{dL}$ ), high low-density lipoprotein cholesterol (LDL-c $>130 \mathrm{mg} / \mathrm{dL}$ ), and low high-density lipoprotein cholesterol (HDL-c $<60 \mathrm{mg} / \mathrm{dL}$ ) [24]. The glycemic profile was analyzed using homeostasis model assessment of insulin resistance (HOMA-IR) as a marker of insulin resistance (IR > 2.72) [25] and high fasting insulinemia ( $25 \mathrm{mU} / \mathrm{L})$ [3], fasting blood glucose, and glycosylated hemoglobin. C-reactive protein (CRP) was classified as nonreactive $(<6 \mathrm{mg} / \mathrm{L})$ or reactive $(>6 \mathrm{mg} / \mathrm{L})$. The following methods were used in the biochemical analyses-colorimetric enzymatic assay to assess fasting blood glucose and lipid profile, electrochemiluminescence to assess fasting insulinemia and HOMA-IR, immunoturbidimetry to assess glycosylated hemoglobin, and semiquantitative CRP.

The presence of T2DM was defined by the use of hypoglycemic agents and/or the following-fasting blood glucose $\geq 126 \mathrm{mg} / \mathrm{dL}$ and glycosylated hemoglobin $\geq 6.5 \%$ (ADA, 2019). Systemic arterial hypertension (SAH) was determined when systolic blood pressure was $\geq 140 \mathrm{mmHg}$ and diastolic blood pressure was $\geq 90 \mathrm{mmHg}$ and/or by antihypertensive drugs use [26]. Blood pressure (BP) in the brachial artery was measured using the automatic sphygmomanometer Omron HEM-742INT (Omron Healthcare, São Paulo, SP, Brazil), with an appropriate cuff size for severely obese individuals. The mean of two measurements taken at rest 2 to 3 min apart was used in BP classification [27]. 


\subsection{Ethical Aspects}

This study follows the Declaration of Helsinki for experiments on human beings. All participants were volunteers and provided written informed consent. The study was approved by the Ethics Committee (protocol No. 747,792/2014).

\subsection{Statistical Analysis}

The prevalence and prevalence ratio (PR) were calculated with a 95\% confidence interval (CI) for all explanatory variables according to the outcome variable T2DM, using the reference category with the lowest frequency in each variable to calculate the PR [28]. The linear trend chi-square test was used between age and T2DM. The normality of continuous data was calculated using the Kolmogorov-Smirnov test. After confirming the normality of the data, the Student's $t$ test was used to calculate parametric data means; Pearson correlation was used between BMI and the following variables_fasting blood glucose, glycosylated hemoglobin, HOMA-IR, and fasting insulinemia.

Variables with a $p$-value $<0.20$ in the bivariate analysis were included in the multivariate analysis using the Poisson regression [28]. There was an adjustment for the use of hypoglycemic agents, with the exception of the variables that are part of the diagnostic criterion of diabetes used to define the outcome of the present study. A $p$-value $<0.05$ was considered statistically significant in all analyses.

\section{Results}

This study included 150 class II and III obese individuals, with a T2DM prevalence of 40\% (95\% CI, 32.1-48.3). The mean age of the study participants was $43.0 \pm 4.4$ years, and the mean BMI was 48.4 $\pm 6.1 \mathrm{~kg} / \mathrm{m}^{2}$. Twenty-seven patients with T2DM (45\%) were using oral antidiabetic agents, mainly metformin $(n=25)$. Only three patients were on insulin therapy.

Lower educational levels $(\mathrm{PR}=1.93,95 \% \mathrm{CI}, 1.32-2.80)$ and age $>50$ years $(\mathrm{PR}=3.17,95 \% \mathrm{CI}$, 1.26-7.98) were significantly associated with T2DM, with a positive linear trend between age and T2DM (Table 1).

SAH, hypertriglyceridemia, and high CRP level were statistically associated with T2DM in class II and III obesity (Table 2). The prevalence of high fasting glucose was $19.33 \%$ (95\% CI, 13.3-26.6) and high glycated hemoglobin was 32.67\% (95\% CI, 25.2-40.8).

The variables included in multiple regression were age and educational level (1st level); consumption of raw vegetables and whole cereals (2nd level); and hypertension, HOMA-IR, fasting insulinemia, hypertriglyceridemia, HDL, and CRP (3rd level). The variables associated with T2DM were lower educational level $(p=0.018)$, nonconsumption of whole grains $(p=0.049)$, and high HOMA-IR ( $p=0.016)$ (Table 3).

There was no significant correlation between BMI and the glycemic parameters fasting blood glucose, glycosylated hemoglobin, HOMA-IR, and insulin (Figure 1). Additionally, in a subgroup analysis, no significant correlation was found between BMI and fasting blood glucose, glycosylated hemoglobin, HOMA-IR, and insulin, respectively-only participants with T2DM $(p=0.372, p=0.807$, $p=0.811, p=0.722)$, participants with T2DM without antidiabetic agents $(p=0.483, p=0.467, p=0.709$, $p=0.734)$, and participants with TD2M on antidiabetic agents $(p=0.465, p=0.153, p=0.459, p=0.438)$. 
Table 1. Prevalence of type 2 diabetes mellitus and its associated factors in class II and III obesity with respect to sociodemographic, lifestyle, and food consumption variables.

\begin{tabular}{|c|c|c|c|c|}
\hline \multirow[b]{2}{*}{ Variables } & \multirow{2}{*}{$\begin{array}{l}\text { Total } \\
n(\%)\end{array}$} & \multicolumn{2}{|c|}{ Diabetes Mellitus } & \multirow{2}{*}{$p$-Value ${ }^{1}$} \\
\hline & & $\begin{array}{c}\text { Prevalence } \\
n(\%)\end{array}$ & PR (95\% CI) & \\
\hline Sex & & & & 0.925 \\
\hline Female & $128(85.33)$ & $51(39.84)$ & 1.00 & \\
\hline Male & $22(14.67)$ & $9(40.91)$ & $1.02(0.59-1.77)$ & \\
\hline Age $^{2}$ & & & & 0.011 \\
\hline $18-29$ years & 19 (12.67) & $4(21.05)$ & 1.00 & \\
\hline 30-39 years & $57(38.00)$ & $22(38.60)$ & $1.83(0.72-4.66)$ & \\
\hline 40-49 years & $53(35.33)$ & $20(37.74)$ & $1.79(0.70-4.59)$ & \\
\hline 50-64 years & $21(14.00)$ & $14(66.67)$ & $3.17(1.26-7.98)$ & \\
\hline Color & & & & 0.400 \\
\hline White & $46(30.67)$ & $16(34.78)$ & 1.00 & \\
\hline Pardo/Black & $104(69.33)$ & $44(42.31)$ & $1.22(0.77-1.92)$ & \\
\hline Marital status & & & & 0.313 \\
\hline Without partner & $55(36.67)$ & $19(34.55)$ & 1.00 & \\
\hline With partner & $95(63.33)$ & $41(43.16)$ & $1.25(0.81-1.92)$ & \\
\hline Educational level & & & & $<0.001$ \\
\hline Up to 8 years of study & $49(32.67)$ & $29(59.18)$ & $1.93(1.32-2.80)$ & \\
\hline$\geq 9$ years of study & $101(67.33)$ & $31(30.69)$ & 1.00 & \\
\hline Economic class & & & & 0.393 \\
\hline $\mathrm{A} / \mathrm{B}$ & $34(22.67)$ & $11(32.35)$ & 1.00 & \\
\hline $\mathrm{C}$ & $92(61.33)$ & $37(40.22)$ & $1.24(0.72-2.15)$ & \\
\hline $\mathrm{D} / \mathrm{E}$ & $24(16.00)$ & $12(50.00)$ & $1.54(0.82-2.91)$ & \\
\hline \multicolumn{5}{|l|}{ Lifestyle } \\
\hline Smoking habits & & & & 0.616 \\
\hline Nonsmoker & $101(67.33)$ & $39(38.61)$ & 1.00 & \\
\hline Smoker or ex-smoker & $49(32.67)$ & $21(42.86)$ & $1.11(0.74-1.67)$ & \\
\hline Physical activity level & & & & 0.208 \\
\hline$<150 \mathrm{~min} /$ week & $132(93.62)$ & $49(37.12)$ & 1.00 & \\
\hline$\geq 150 \mathrm{~min} /$ week & $9(6.38)$ & $5(55.56)$ & $1.49(0.79-2.80)$ & \\
\hline \multicolumn{5}{|l|}{ Food consumption } \\
\hline Raw vegetables & & & & 0.133 \\
\hline Not daily & $81(54.00)$ & $37(45.68)$ & $1.37(0.91-2.07)$ & \\
\hline Daily & $69(46.00)$ & $23(33.33)$ & 1.00 & \\
\hline Cooked vegetables & & & & 0.882 \\
\hline Not daily & 109 (72.67) & $44(40.37)$ & $1.03(0.66-1.62)$ & \\
\hline Daily & $41(27.33)$ & $16(39.02)$ & 1.00 & \\
\hline Fresh fruit & & & & 1.000 \\
\hline Not daily & $110(73.33)$ & $44(40.00)$ & $1.00(0.64-1.56)$ & \\
\hline Daily & $40(26.67)$ & $16(40.00)$ & 1.00 & \\
\hline Whole-grain cereals & & & & 0.145 \\
\hline Not daily & $126(84.00)$ & $54(42.86)$ & $1.71(0.83-3.54)$ & \\
\hline Daily & $24(16.00)$ & $6(25.00)$ & 1.00 & \\
\hline Sweets and candy & & & & 0.815 \\
\hline Not daily & $136(90.67)$ & $54(39.71)$ & 1.00 & \\
\hline Daily & $14(9.33)$ & $6(42.86)$ & $1.08(0.57-2.05)$ & \\
\hline Sugary drinks & & & & 0.536 \\
\hline Not daily & $98(65.33)$ & $41(41.84)$ & $1.14(0.74-1.76)$ & \\
\hline Daily & $52(34.67)$ & $19(36.54)$ & 1.00 & \\
\hline Meal fractionation & & & & 0.349 \\
\hline$<3$ meals/day & $31(20.67)$ & $10(32.26)$ & 1.00 & \\
\hline$\geq 3$ meals/day & $119(79.33)$ & $50(42.02)$ & $1.30(0.75-2.27)$ & \\
\hline
\end{tabular}

PR, prevalence ratio; CI, confidence interval. ${ }^{1}$ Chi-square. ${ }^{2}$ Linear chi-square, $p=0.011$. Bold: $p<0.05$. 
Table 2. Prevalence of type 2 diabetes mellitus and its associated factors in class II and III obesity with respect to systemic arterial hypertension, biochemical parameters, obesity class, and body composition.

\begin{tabular}{|c|c|c|c|c|}
\hline \multirow[b]{2}{*}{ Variables } & \multirow{2}{*}{$\begin{array}{l}\text { Total } \\
n(\%)\end{array}$} & \multicolumn{2}{|c|}{ Diabetes Mellitus } & \multirow{2}{*}{$p$-Value ${ }^{1}$} \\
\hline & & $\begin{array}{c}\text { Prevalence } \\
n(\%)\end{array}$ & PR (95\% CI) & \\
\hline Arterial hypertension & & & & 0.002 \\
\hline No & $65(43.33)$ & $16(24.62)$ & 1.00 & \\
\hline Yes & 85 (56.67) & $44(51.76)$ & $2.10(1.31-3.78)$ & \\
\hline \multicolumn{5}{|l|}{ Biochemical parameters } \\
\hline High HOMA-IR & & & & 0.109 \\
\hline No & $101(67.33)$ & $36(35.64)$ & 1.00 & \\
\hline Yes & $49(32.67)$ & $24(48.98)$ & $1.37(0.93-2.03)$ & \\
\hline High fasting insulinemia & & & & 0.093 \\
\hline No & $23(15.33)$ & $5(21.74)$ & 1.00 & \\
\hline Yes & $127(54.67)$ & $55(43.31)$ & $1.99(0.89-4.45)$ & \\
\hline Hypercholesterolemia & & & & 0.891 \\
\hline No & $94(62.67)$ & $38(40.43)$ & $0.97(0.64-1.46)$ & \\
\hline Yes & $56(37.33)$ & $22(39.29)$ & 1.00 & \\
\hline Hypertriglyceridemia & & & & 0.015 \\
\hline No & $81(54.00)$ & $25(30.86)$ & 1.00 & \\
\hline Yes & $69(46.00)$ & $35(50.72)$ & $1.64(1.10-2.46)$ & \\
\hline High LDL-c & & & & 0.739 \\
\hline No & $113(76.87)$ & $47(41.59)$ & $1.09(0.67-1.76)$ & \\
\hline Yes & $34(23.13)$ & $13(38.24)$ & 1.00 & \\
\hline Low HDL-c & & & & 0.118 \\
\hline No & $14(9.33)$ & $8(57.14)$ & $1.49(0.90-2.47)$ & \\
\hline Yes & $136(90.67)$ & $52(38.24)$ & 1.00 & \\
\hline CRP & & & & 0.046 \\
\hline Nonreactive & $63(42.00)$ & $19(30.16)$ & 1.00 & \\
\hline Reactive & $87(58.00)$ & $41(47.13)$ & $1.56(1.01-2.42)$ & \\
\hline BMI & & & & 0.894 \\
\hline $35.0-44.9 \mathrm{~kg} / \mathrm{m}^{2}$ & $76(50.67)$ & $30(39.47)$ & 1.00 & \\
\hline$\geq 45.0 \mathrm{~kg} / \mathrm{m}^{2}$ & $74(49.33)$ & $30(40.54)$ & $1.03(0.69-1.52)$ & \\
\hline \multicolumn{5}{|l|}{ Body composition } \\
\hline Total body fat, $\%$ & & & & 0.976 \\
\hline 1st and 2nd quartiles & $71(48.97)$ & $28(49.12)$ & 1.00 & \\
\hline 3rd and 4th quartiles & $74(51.03)$ & $29(50.88)$ & $0.99(0.66-1.49)$ & \\
\hline Total fat mass, $\mathrm{kg}$ & & & & 0.918 \\
\hline 1st and 2nd quartiles & $72(49.66)$ & $28(49.12)$ & 1.00 & \\
\hline 3rd and 4th quartiles & $73(50.34)$ & $29(50.88)$ & $1.02(0.68-1.53)$ & \\
\hline Fat-free mass, kg & & & & 0.293 \\
\hline 1st and 2nd quartiles & $71(48.97)$ & $31(54.39)$ & $1.24(0.83-1.87)$ & \\
\hline \multirow[t]{3}{*}{ 3rd and 4th quartiles } & $74(51.03)$ & $26(45.61)$ & 1.00 & \\
\hline & Total & Nondiabetic & Diabetic & $p$-value ${ }^{2}$ \\
\hline & Mean \pm SD & Mean \pm SD & Mean \pm SD & \\
\hline Total body fat, $\%$ & $51.58 \pm 4.68$ & $51.32 \pm 4.50$ & $51.98 \pm 4.97$ & 0.409 \\
\hline Total fat mass, $\mathrm{kg}$ & $61.44 \pm 12.96$ & $61.84 \pm 13.42$ & $60.82 \pm 12.30$ & 0.647 \\
\hline Fat-free mass, $\mathrm{kg}$ & $57.32 \pm 8.95$ & $58.05 \pm 9.52$ & $56.19 \pm 7.93$ & 0.221 \\
\hline
\end{tabular}

HOMA-IR, homeostasis model assessment of insulin resistance; LDL-c, low-density lipoprotein cholesterol; HDL-c, high-density lipoprotein cholesterol; CRP, C-reactive protein; BMI, body mass index; PR, prevalence ratio; CI, confidence interval; SD, standard deviation. ${ }^{1}$ Chi-square. ${ }^{2}$ Student's $t$-test. Bold: $p<0.05$. 
Table 3. Variables associated with type 2 diabetes mellitus in class II and III obese individuals after hierarchical multivariate analysis and adjustment for hypoglycemic agent use.

\begin{tabular}{|c|c|c|}
\hline \multirow{2}{*}{ Variables } & Diabetes Mellitus & \multirow{2}{*}{$p$-Value ${ }^{1}$} \\
\hline & Adjusted PR (95\% CI) & \\
\hline \multicolumn{3}{|l|}{ 1st level } \\
\hline \multicolumn{3}{|l|}{ Age } \\
\hline $18-29$ years & 1.00 & \\
\hline 30-39 years & $1.84(0.86-3.96)$ & 0.117 \\
\hline 40-49 years & $1.23(0.59-2.60)$ & 0.589 \\
\hline 50-64 years & $1.89(0.86-4.14)$ & 0.111 \\
\hline \multicolumn{3}{|l|}{ Educational level } \\
\hline Up to 8 years of study & $1.49(1.07-2.09)$ & 0.018 \\
\hline$\geq 9$ years of study & 1.00 & \\
\hline \multicolumn{3}{|l|}{ 2nd level } \\
\hline \multicolumn{3}{|c|}{ Raw vegetable consumption } \\
\hline Not daily & $1.04(0.73-1.49)$ & 0.822 \\
\hline Daily & 1.00 & \\
\hline \multicolumn{3}{|c|}{ Whole-grain cereal consumption } \\
\hline Not daily & $1.67(1.00-2.80)$ & 0.049 \\
\hline Daily & 1.00 & \\
\hline \multicolumn{3}{|l|}{ 3rd level } \\
\hline \multicolumn{3}{|l|}{ Low HDL-c } \\
\hline No & $1.05(0.69-1.59)$ & 0.805 \\
\hline Yes & 1.00 & \\
\hline \multicolumn{3}{|l|}{ High fasting insulinemia } \\
\hline No & 1.00 & \\
\hline Yes & $1.29(0.63-2.65)$ & 0.480 \\
\hline \multicolumn{3}{|l|}{ CRP } \\
\hline Nonreactive & 1.00 & \\
\hline Reactive & $1.19(0.79-1.78)$ & 0.401 \\
\hline \multicolumn{3}{|l|}{ Hypertension } \\
\hline No & 1.00 & \\
\hline Yes & $1.29(0.82-2.02)$ & 0.270 \\
\hline \multicolumn{3}{|l|}{ Hypertriglyceridemia } \\
\hline No & 1.00 & \\
\hline Yes & $1.37(0.96-1.93)$ & 0.077 \\
\hline \multicolumn{3}{|l|}{ High HOMA-IR } \\
\hline No & 1.00 & \\
\hline Yes & $1.54(1.08-2.18)$ & 0.016 \\
\hline
\end{tabular}

HDL-c, high-density lipoprotein cholesterol; CRP, C-reactive protein; HOMA-IR, homeostasis model assessment of insulin resistance; PR, prevalence ratio; CI, confidence interval. ${ }^{1}$ Chi-square. Bold: $p<0.05$. 


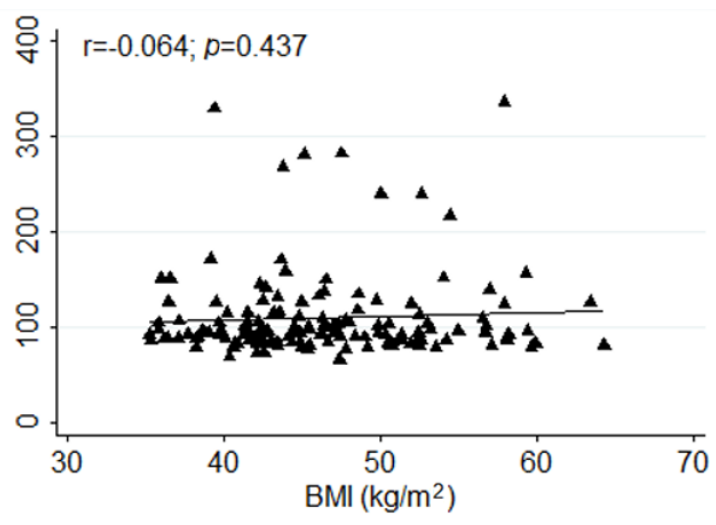

(a)

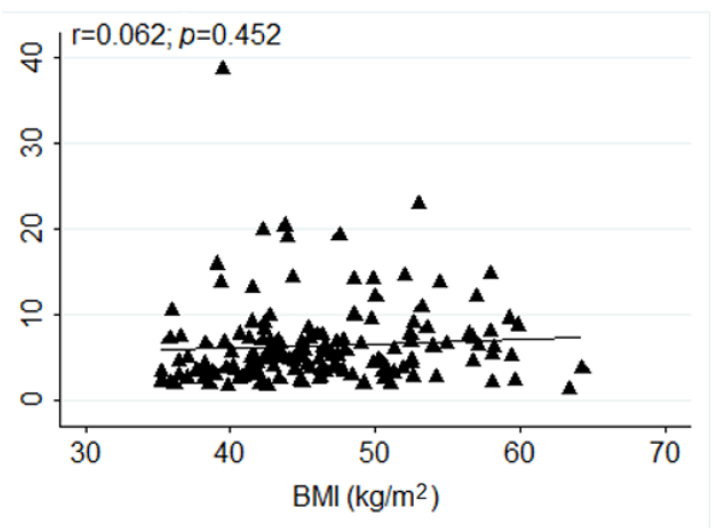

(c)

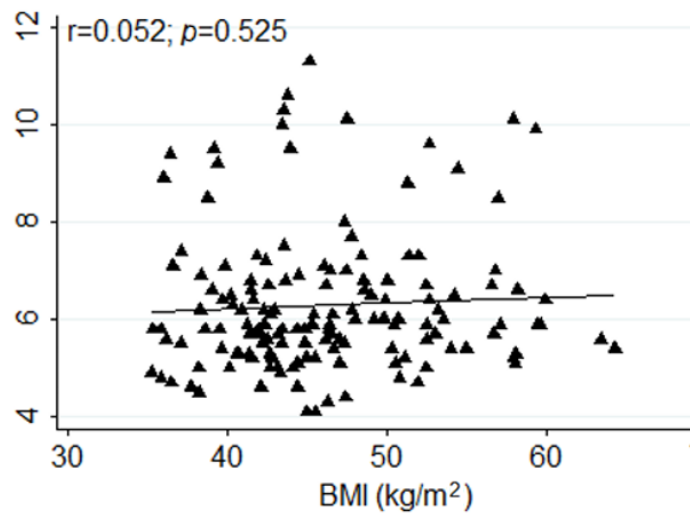

(b)

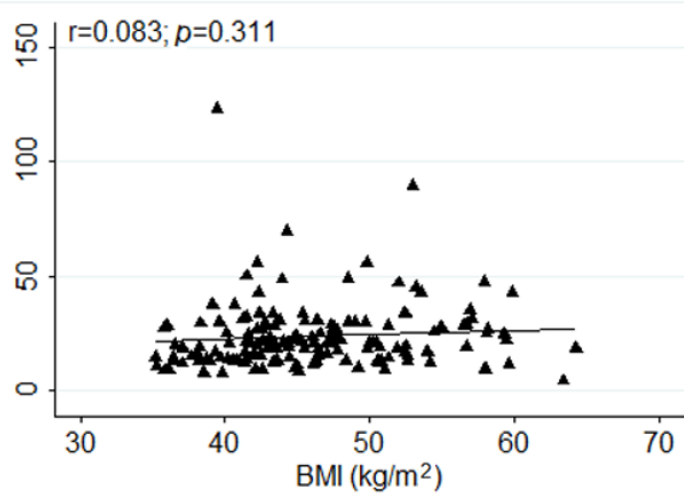

(d)

Figure 1. Correlation between body mass index and glycemic parameters in class II and III obesity ((a). fasting blood glucose, (b). glycosylated hemoglobin, (c). homeostasis model assessment of insulin resistance, (d). insulin).

\section{Discussion}

The present study is an important contribution to T2DM and obesity research as it is one of the few studies to evaluate T2DM-associated factors specifically in class II and III obese individuals not having undergone previous bariatric surgery [7]. In addition, this study also fills a gap in the analysis of food consumption and body composition, as well as in the correlation between BMI and glycemic profile, which are variables poorly investigated in the class II and III obese population. The results show a high prevalence of T2DM (40\%) in this population, with the associated risks being lower educational level, nonconsumption of whole grains, and high HOMA-IR. Because there are no previous studies on T2DM in class II and III obesity, it is impossible to compare results; however, this emphasizes the relevance of these findings.

The association between lower educational level and T2DM in class II and III obesity corroborates other studies in which the same association was reported $[29,30]$, as well as in individuals with a normal BMI [31]. Lower educational level is an important variable as it can influence the treatment of obesity due to the difficulty in understanding the guidelines or prescriptions proposed by healthcare professionals [29,32-34]. Therefore, identifying the appropriate approach and more understandable strategies for those with lower educational attainment as a way to improve clinical treatment and increase compliance is a challenge for the multidisciplinary healthcare team. In addition, lower educational levels are associated with low socioeconomic status, directly implying reduced access to 
agile and continuous healthcare services and decreased access to healthy food, equipment for regular PA, and participation in regular PA programs [35-39].

This study showed an association between nonconsumption of whole grains daily and T2DM in class II and III obesity. Low whole-grain consumption can be influenced by large supplies of ultraprocessed foods combined with the lower price of these products [40]. It has been reported that whole grains are less accepted, which is related to the limited time and ability to prepare these foods, low financial conditions to purchase them, and low availability of products in the supermarkets [41,42]. Consequently, the reduced consumption of whole grains may also reflect the general quality of the diet, which tends to be low in fiber, playing an essential role in the control of body weight and lipid and glycemic profiles $[13,43,44]$. Evidence suggests that a diet rich in whole grains and vegetables with reduced consumption of refined grains, sucrose, and fructose may have a protective role against diabetes $[13,40,43]$.

The association between HOMA-IR and T2DM in class II and III obesity identified in this study reinforces the IR status. An increased HOMA-IR is a common feature for T2DM in obese individuals due to a greater production of inflammatory markers by the visceral adipose tissue and lower levels of adiponectin, a condition that favors IR and T2DM [45-47]. One cohort study showed that IR obese individuals had more abdominal fat, higher CRP levels, and lower adiponectin levels compared with nonresistant individuals ( $p=0.015$ to $<0.0001$ ) [48]. HOMA-IR is one of the most frequently used indicators for T2DM prognosis and control; higher values are associated with a higher risk of diabetic retinopathy, neuropathy, nephropathy, coronary artery disease, and peripheral vascular disease [49,50]. On the other hand, a European study of nondiabetic individuals with different BMI ranges did not find an association between obesity and insulin resistance, where prevalence of insulin resistance was relatively low [51]. This study also show that obesity per se is not the only factor causing diabetes, and it is necessary to have insulin resistance with obesity to develop T2DM [51].

This study showed no association between T2DM and body composition, inflammatory markers, or lipid profile, in contrast to a study by Fronczyk et al. [52], which reported that BMI $(p<0.0001)$ and presence of diabetes $(p=0.011)$ are independent factors increasing CRP levels. As for the lipid profile, compared with nondiabetic obese individuals, obese diabetic individuals presented with increased total cholesterol $(p<0.001)$, triglycerides $(p<0.001)$, and LDL-c $(p<0.001)$ levels $[48,53]$.

Despite the hypothesis that increased BMI correlates with glycemic profile parameters in studies on preobesity [54-56], this correlation was not observed in the present study. These results highlight the importance of deepening knowledge about T2DM, specifically in severely obese individuals. A previous study of severely obese individuals reported that increased obesity levels were a factor associated with worsening glucose homeostasis when compared with other obesity classes [7]. Cardiometabolic complications are more prevalent and severe in these individuals than in less obese individuals [7].

One of the limitations of this study is the difficulty in measuring eating habits. However, this is inherent to the food frequency instrument itself, which has been widely used in research in this area [57]. As there is no instrument specifically validated to analyze class II and III obesity, the instrument used in this study was the FFQ, as recommended for population-based studies with adults [58]. In this study, several methodological precautions, such as the training of interviewers and nutritionists, improvement of the questionnaire in a pilot study, and the development of Standardized Operating Procedures for all stages of the research, were taken to ensure the quality of the data collected. The instruments used in the present study, such as triaxial accelerometer and multifrequency BIA, were all previously calibrated and reinforced the quality of the data.

\section{Conclusions}

To summarize, the risk factors associated with a high prevalence of T2DM in class II and III obesity were found to be lower educational level, nonconsumption of whole grains, and high HOMA-IR values. There was no correlation between BMI and glycemic parameters, that is, an increased BMI did not directly affect a decline in the metabolic condition of T2DM individuals. It is important to emphasize 
the need to perform further research on T2DM in this specific class II and III obese population. Future studies should analyze food consumption, body composition, and metabolic, glycemic, and inflammatory parameters to increase knowledge in this area, contributing to the development of T2DM prevention and the establishment of specific clinical protocols for this population.

Author Contributions: Conceptualization, E.A.S. and L.P.d.S.R.; Formal analysis, E.A.S., L.P.d.S.R. and A.S.e.A.d.C.S.; Funding acquisition, E.A.S., A.S.e.A.d.C.S. and M.N.; Investigation, E.A.S., L.P.d.S.R., A.S.e.A.d.C.S. and C.K.d.S.C.; Methodology, E.A.S., L.P.d.S.R., A.S.e.A.d.C.S., C.K.d.S.C. and M.N.; Supervision, E.A.S.; Validation, L.P.d.S.R.; Visualization, E.A.S., A.S.e.A.d.C.S., C.K.d.S.C. and M.N.; Writing-original draft, E.A.S., L.P.d.S.R., and M.N.; Writing - review \& editing, E.A.S., L.P.d.S.R., A.S.e.A.d.C.S., C.K.d.S.C. and M.N.; Principal investigator, E.A.S. All authors have read and agreed to the published version of the manuscript.

Funding: This research was funded by Research Support Foundation of the State of Goiás (FAPEG), grant number 201310267000003 and the Coordination for the Improvement of Higher Education Personnel (CAPES), granting doctoral scholarships to A.S.e.A.d.C.S. and C.K.d.S.C.

Acknowledgments: We would like to thank all study participants and undergraduate volunteers who participated in our study; Goiano Federal Institute for partial supporting; and all the Clinical Research Unit/UFG staff. We would also like to thank the Nutrition in Severe Obesity Outpatient Clinic (ANOG); Clinical Hospital/UFG; and the Goiânia Municipal Health Secretariat. We thank all DieTBra Trial researchers for their effort to produce this high-quality research.

Conflicts of Interest: The authors declare no conflict of interest.

\section{References}

1. NCD Risk Factor Collaboration. Trends in adult body-mass index in 200 countries from 1975 to 2014 : A pooled analysis of 1698 population-based measurement studies with 19.2 million participants. Lancet 2016, 387, 1377-1396. [CrossRef]

2. Santos, A.S.A.C.; Rodrigues, A.P.S.; Rosa, L.P.S.; Sarrafzadegan, N.; Silveira, E.A. Cardiometabolic risk factors and Framingham Risk Score in severely obese patients: Baseline data from DieTBra trial. Nutr. Metab. Cardiovasc. Dis. 2020, 3, 474-482. [CrossRef] [PubMed]

3. Association, A.D. Standards of Medical Care in Diabetes-2017. Available online: https://care. diabetesjournals.org/content/diacare/suppl/2016/12/15/40.Supplement_1.DC1/DC_40_S1_final.pdf (accessed on 10 October 2019).

4. International Diabetes Federation. IDF Diabetes Atlas [Internet], 9th ed.; International Diabetes Federation: Brussels, Belgium, 2019.

5. Leitner, D.R.; Frühbeck, G.; Yumuk, V.; Schindler, K.; Micic, A.; Woodward, E.; Toplak, H. Obesity and Type 2 Diabetes: Two Diseases with a Need for Combined Treatment Strategies-EASO Can Lead the Way. Obes. Facts 2017, 10, 483-492. [CrossRef] [PubMed]

6. Zhang, L.; Wang, J.; Zhang, M.; Wang, G.; Shen, Y.; Wu, D.; Wang, C.; Li, L.; Ren, Y.; Wang, B.; et al. Association of type 2 diabetes mellitus with the interaction between low-density lipoprotein receptor-related protein 5 (LRP5) polymorphisms and overweight and obesity in rural Chinese adults. J. Diabetes 2017, 9, 994-1002. [CrossRef]

7. Vinciguerra, F.; Baratta, R.; Farina, M.G.; Tita, P.; Padova, G.; Vigneri, R.; Frittitta, L. Very severely obese patients have a high prevalence of type 2 diabetes mellitus and cardiovascular disease. Acta Diabetol. 2013, 50, 443-449. [CrossRef]

8. Abbatini, F.; Capoccia, D.; Casella, G.; Soricelli, E.; Leonetti, F.; Basso, N. Long-term remission of type 2 diabetes in morbidly obese patients after sleeve gastrectomy. Surg. Obes. Relat. Dis. 2013, 9, 498-502. [CrossRef]

9. Hariri, K.; Guevara, D.; Jayaram, A.; Kini, S.; Herron, D.M.; Fernandez-Ranvier, G. Preoperative insulin therapy as a marker for type 2 diabetes remission in obese patients after bariatric surgery. Surg. Obes. Relat. Dis. 2018, 14, 332-337. [CrossRef]

10. Bailly, L.; Schiavo, L.; Sebastianelli, L.; Fabre, R.; Morisot, A.; Pradier, C.; Iannelli, A.; Schneck, A.-S. Preventive effect of bariatric surgery on type 2 diabetes onset in morbidly obese inpatients: A national French survey between 2008 and 2016 on 328,509 morbidly obese patients. Surg. Obes. Relat. Dis. 2019, 15, 478-487. [CrossRef] 
11. Tilles-Tirkkonen, T.; Aittola, K.; Männikkö, R.; Absetz, P.; Kolehmainen, M.; Schwab, U.; Lindstrom, J.; Lakka, T.A.; Pihlajamäki, J.; Karhunen, L. Eating Competence Is Associated with Lower Prevalence of Obesity and Better Insulin Sensitivity in Finnish Adults with Increased Risk for Type 2 Diabetes: The StopDia Study. Nutrients 2019, 12, 104. [CrossRef]

12. Ley, S.H.; Korat, A.V.A.; Sun, Q.; Tobias, D.K.; Zhang, C.-L.; Qi, L.; Willett, W.C.; Manson, J.E.; Hu, F.B. Contribution of the Nurses' Health Studies to Uncovering Risk Factors for Type 2 Diabetes: Diet, Lifestyle, Biomarkers, and Genetics. Am. J. Public Health 2016, 106, 1624-1630. [CrossRef]

13. A Gaesser, G.; Whisner, C.M.; Angadi, S.S.; Rodriguez, J.; Patrie, J.T. Effects of Glycemic Index and Cereal Fiber on Postprandial Endothelial Function, Glycemia, and Insulinemia in Healthy Adults. Nutrients 2019, 11, 2387. [CrossRef] [PubMed]

14. Henry, R.R.; Chilton, R.; Garvey, W.T. New options for the treatment of obesity and type 2 diabetes mellitus (narrative review). J. Diabetes Complicat. 2013, 27, 508-518. [CrossRef] [PubMed]

15. Rodrigues, A.P.; Rosa, L.P.S.; Silva, H.D.; Silveira-Lacerda, E.D.P.; Silveira, E.A. The Single Nucleotide Polymorphism PPARG2 Pro12Ala Affects Body Mass Index, Fat Mass, and Blood Pressure in Severely Obese Patients. J. Obes. 2018, 2018, 1-9. [CrossRef] [PubMed]

16. Rodrigues, A.P.S.; Rosa, L.P.S.; Silveira, E.A. PPARG2 Pro12Ala polymorphism influences body composition changes in severely obese patients consuming extra virgin olive oil: A randomized clinical trial. Nutr. Metab. 2018, 15, 52. [CrossRef] [PubMed]

17. Cardoso, C.K.D.S.; Santos, A.S.E.A.D.C.; Rosa, L.P.D.S.; De Mendonça, C.R.; Vitorino, P.V.D.O.; Peixoto, M.D.R.G.; Silveira, E.A. Effect of Extra Virgin Olive Oil and Traditional Brazilian Diet on the Bone Health Parameters of Severely Obese Adults: A Randomized Controlled Trial. Nutrients 2020, 12, 403. [CrossRef] [PubMed]

18. Dillon, C.; Fitzgerald, A.P.; Kearney, P.M.; Perry, I.J.; Rennie, K.L.; Kozarski, R.; Phillips, C.M. Number of Days Required to Estimate Habitual Activity Using Wrist-Worn GENEActiv Accelerometer: A Cross-Sectional Study. PLoS ONE 2016, 11, e0109913. [CrossRef]

19. Furlan-Viebig, R.; Pastor-Valero, M. Development of a food frequency questionnaire to study diet and non-communicable diseases in adult population. Rev. Saude Publica 2004, 38, 581-584. [CrossRef]

20. Lohman, T.G.; Roche, A.F.; Martorell, R. Anthropometric Standardization Reference Mmanual; Human Kinetics Books: Champaign, IL, USA, 1988.

21. World Health Organization. Obesity: Preventing and managing the global epidemic. In Report of a WHO Consultation; World Health Organization Technical Report Series; World Health Organization: Geneva, Switzerland, 2000.

22. Horie, L.M.; Gonzalez, M.C.; Torrinhas, R.S.; Cecconello, I.; Waitzberg, D.L. New Specific Equation to Estimate Resting Energy Expenditure in Severely Obese Patients. Obesity 2011, 19, 1090-1094. [CrossRef]

23. Kyle, U.G.; Bosaeus, I.; De Lorenzo, A.D.; Deurenberg, P.; Elia, M.; Gómez, J.M.; Heitmann, B.L.; Kent-Smith, L.; Melchior, J.-C.; Pirlich, M.; et al. Bioelectrical impedance analysis-Part II: Utilization in clinical practice. Clin. Nutr. 2004, 23, 1430-1453. [CrossRef]

24. Third Report of the National Cholesterol Education Program (NCEP). Expert Panel on Detection, Evaluation, and Treatment of High Blood Cholesterol in Adults (Adult Treatment Panel III) Final Report. Circulation 2002, 106, 3143. [CrossRef]

25. Geloneze, B.; Repetto, E.M.; Geloneze, S.R.; Tambascia, M.A.; Ermetice, M.N. The threshold value for insulin resistance (HOMA-IR) in an admixtured population. Diabetes Res. Clin. Pract. 2006, 72, 219-220. [CrossRef] [PubMed]

26. Faludi, A.; Izar, M.; Saraiva, J.; Chacra, A.; Bianco, H.; Neto, A.A.; Bertolami, A.; Pereira, A.; Lottenberg, A.; Sposito, A.C.; et al. ATUALIZAÇÃO DA DIRETRIZ BRASILEIRA DE DISLIPIDEMIAS E PREVENÇÃO DA ATEROSCLEROSE-2017. Arq. Bras. Cardiol. 2017, 109. [CrossRef] [PubMed]

27. Frese, E.M.; Fick, A.; Sadowsky, S.H. Blood Pressure Measurement Guidelines for Physical Therapists. Cardiopulm. Phys. Ther. J. 2011, 22, 5-12. [CrossRef] [PubMed]

28. Barros, A.J.; Hirakata, V.N. Alternatives for logistic regression in cross-sectional studies: An empirical comparison of models that directly estimate the prevalence ratio. BMC Med. Res. Methodol. 2003, 3, 21. [CrossRef] [PubMed] 
29. Rodrigues, A.P.S.; Silveira, E.A. Correlation and association of income and educational level with health and nutritional conditions among the morbidly obese. Cienc. Saude Coletiva 2015, 20, 165-175. [CrossRef] [PubMed]

30. Ceriello, A.; Esposito, K.; La Sala, L.; Pujadas, G.; De Nigris, V.; Testa, I.; Bucciarelli, L.; Rondinelli, M.; Genovese, S. The protective effect of the Mediterranean diet on endothelial resistance to GLP-1 in type 2 diabetes: A preliminary report. Cardiovasc. Diabetol. 2014, 13, 140. [CrossRef]

31. Malta, D.C.; Bernal, R.T.I.; Nunes, M.L.; De Oliveira, M.M.; Iser, B.P.M.; Andrade, S.S.C.D.A.; Claro, R.M.; Monteiro, C.A.; Barbosa da Silva, J., Jr. Prevalência de fatores de risco e proteção para doenças crônicas não transmissíveis em adultos: Estudo transversal, Brasil 2012. Epidemiologia e Serviços de Saúde 2014, 23, 609-622. [CrossRef]

32. Adam, K.D.; Wendel, C.S.; Solvas, P.A.; Hoffman, R.M.; Duckworth, W.C.; Murata, G.H.; Shah, J.H.; Bokhari, S.U. Factors affecting diabetes knowledge in Type 2 diabetic veterans. Diabetologia 2003, 46, 1170-1178. [CrossRef]

33. Delamater, A.M. Improving Patient Adherence. Clin. Diabetes 2006, 24, 71-77. [CrossRef]

34. Lins, A.P.M.; Sichieri, R.; Coutinho, W.F.; Ramos, E.G.; Peixoto, M.V.M.; Fonseca, V.M. Healthy eating, schooling and being overweight among low-income women. Ciência Saúde Coletiva 2013, 18, 357-366. [CrossRef]

35. Kyrou, I.; On behalf of the Feel4Diabetes-Study Group; Tsigos, C.; Mavrogianni, C.; Cardon, G.; Van Stappen, V.; Latomme, J.; Kivelä, J.; Wikström, K.; Tsochev, K.; et al. Sociodemographic and lifestyle-related risk factors for identifying vulnerable groups for type 2 diabetes: A narrative review with emphasis on data from Europe. BMC Endocr. Disord. 2020, 20, 134. [CrossRef] [PubMed]

36. Denova-Gutiérrez, E.; Vargas-Chanes, D.; Hernández, S.; Muñoz-Aguirre, P.; Napier, D.; Barquera, S. Linking socioeconomic inequalities and type 2 diabetes through obesity and lifestyle factors among Mexican adults: A structural equations modeling approach. Salud Publica Mex. 2020, 62, 192. [CrossRef] [PubMed]

37. Brinkman, H.-J.; de Pee, S.; Sanogo, I.; Subran, L.; Bloem, M.W. High Food Prices and the Global Financial Crisis Have Reduced Access to Nutritious Food and Worsened Nutritional Status and Health. J. Nutr. 2010, 140, 153S-161S. [CrossRef] [PubMed]

38. Olah, M.E.; Gaisano, G.; Hwang, S.W. The effect of socioeconomic status on access to primary care: An audit study. Can. Med. Assoc. J. 2013, 185, E263-E269. [CrossRef]

39. Lim, K.K.; Lim, C.; Kwan, Y.H.; Chan, S.Y.; Fong, W.; Low, L.L.; Tay, H.Y.; Østbye, T.; Tan, C.S. Association between access to health-promoting facilities and participation in cardiovascular disease (CVD) risk screening among populations with low socioeconomic status (SES) in Singapore. Prim. Health Care Res. Dev. 2019, 20, e98. [CrossRef]

40. Fukui, M.; Tanaka, M.; Toda, H.; Senmaru, T.; Sakabe, K.; Ushigome, E.; Asano, M.; Yamazaki, M.; Hasegawa, G.; Imai, S.; et al. Risk factors for development of diabetes mellitus, hypertension and dyslipidemia. Diabetes Res. Clin. Pract. 2011, 94, e15-e18. [CrossRef]

41. Arvola, A.; Lähteenmäki, L.; Dean, M.; Vassallo, M.; Winkelmann, M.; Claupein, E.; Saba, A.; Shepherd, R. Consumers' beliefs about whole and refined grain products in the UK, Italy and Finland. J. Cereal Sci. 2007, 46, 197-206. [CrossRef]

42. Whitelock, V.; Nouwen, A.; van den Akker, O.; Higgs, S. The role of working memory sub-components in food choice and dieting success. Appetite 2018, 124, 24-32. [CrossRef]

43. Velázquez-López, L.; Muñoz-Torres, A.V.; García-Peña, C.; López-Alarcón, M.; Islas-Andrade, S.; Escobedo-de la Peña, J. Fiber in Diet Is Associated with Improvement of Glycated Hemoglobin and Lipid Profile in Mexican Patients with Type 2 Diabetes. J. Diabetes Res. 2016, 2016, 1-9. [CrossRef]

44. Hadrévi, J.; Søgaard, K.; Christensen, J.R. Dietary Fiber Intake among Normal-Weight and Overweight Female Health Care Workers: An Exploratory Nested Case-Control Study within FINALE-Health. J. Nutr. Metab. 2017, 2017, 1-7. [CrossRef]

45. Ellulu, M.S.; Patimah, I.; Khaza'ai, H.; Rahmat, A.; Abed, Y. Obesity and inflammation: The linking mechanism and the complications. Arch. Med. Sci. 2017, 4, 851-863. [CrossRef] [PubMed]

46. Wiebe, N.; Stenvinkel, P.; Tonelli, M. Associations of Chronic Inflammation, Insulin Resistance, and Severe Obesity With Mortality, Myocardial Infarction, Cancer, and Chronic Pulmonary Disease. JAMA Netw. Open 2019, 2, e1910456. [CrossRef] [PubMed] 
47. Schmidt, M.I.; Duncan, B.B.; E Silva, G.A.; Menezes, A.M.; Monteiro, C.A.; Barreto, S.M.; Chor, D.; Menezes, P.R. Chronic non-communicable diseases in Brazil: Burden and current challenges. Lancet 2011, 377, 1949-1961. [CrossRef]

48. Owei, I.; Umekwe, N.; Provo, C.; Wan, J.; Dagogo-Jack, S. Insulin-sensitive and insulin-resistant obese and non-obese phenotypes: Role in prediction of incident pre-diabetes in a longitudinal biracial cohort. BMJ Open Diabetes Res. Care 2017, 5, e000415. [CrossRef]

49. Purohit, D.A.; Tiwari, D.V. To Study Insulin Resistance in Type 2 Diabetes Mallitus by Homa-IR Score. Int. J. Med. Res. Rev. 2015, 3, 3-9. [CrossRef]

50. Adiels, M.; Borén, J.; Caslake, M.J.; Stewart, P.; Soro, A.; Westerbacka, J.; Wennberg, B.; Olofsson, S.-O.; Packard, C.; Taskinen, M.-R. Overproduction of VLDL 1 Driven by Hyperglycemia Is a Dominant Feature of Diabetic Dyslipidemia. Arterioscler. Thromb. Vasc. Biol. 2005, 25, 1697-1703. [CrossRef]

51. Ferrannini, E.; Natali, A.; Bell, P.; Cavallo-Perin, P.; Lalic, N.; Mingrone, G. Insulin resistance and hypersecretion in obesity. European Group for the Study of Insulin Resistance (EGIR). J. Clin. Investig. 1997, 100, 1166-1173. [CrossRef]

52. Fronczyk, A.; Molęda, P.; Safranow, K.; Piechota, W.; Majkowska, L. Increased Concentration of C-Reactive Protein in Obese Patients with Type 2 Diabetes Is Associated with Obesity and Presence of Diabetes but Not with Macrovascular and Microvascular Complications or Glycemic Control. Inflammation 2014, 37, 349-357. [CrossRef]

53. Yadav, N.K.; Thanpari, C.; Shrewastwa, M.; Mittal, R. Comparison of Lipid Profile in Type-2 Obese Diabetics and Obese Non-diabetic Individuals. A hospital Based Study from Western Nepal. Kathmandu Univ. Med. J. 2013, 10, 44-47. [CrossRef]

54. Colditz, G.A. Weight Gain as a Risk Factor for Clinical Diabetes Mellitus in Women. Ann. Intern. Med. 1995, 122, 481. [CrossRef]

55. Vistisen, D.; Witte, D.; Tabak, A.G.; Herder, C.; Brunner, E.J.; Kivimaki, M.; Færch, K. Patterns of Obesity Development before the Diagnosis of Type 2 Diabetes: The Whitehall II Cohort Study. PLoS Med. 2014, 11, e1001602. [CrossRef] [PubMed]

56. Esposito, K.; Maiorino, M.I.; Ceriello, A.; Giugliano, D. Prevention and control of type 2 diabetes by Mediterranean diet: A systematic review. Diabetes Res. Clin. Pract. 2010, 89, 97-102. [CrossRef] [PubMed]

57. Forman, M. Nutritional Epidemiology. Am. J. Clin. Nutr. 1999, 69, 1020. [CrossRef]

58. Pedraza, D.F.; De Menezes, T.N. Food Frequency Questionnaire developed and validated for the Brazilian population: A review of the literature. Ciência Saúde Coletiva 2015, 20, 2697-2720. [CrossRef] 